\title{
Karrikinolide Promotes Seed Germination but Has no Effect on Leaf Segment Senescence in Triticum aestivum L.
}

\author{
Nihal Goren-Saglam ${ }^{10}$, Kevser Duygun ${ }^{1}$ (D), Gulay Kaya ${ }^{2}$ (D) Filiz Vardar $^{3}$ (D) \\ IIstanbul University, Faculty of Science, Department of Biology, Istanbul, Turkey \\ ${ }^{2}$ Recep Tayyip Erdogan University, Faculty of Arts and Sciences, Department of Biology, Rize, Turkey \\ ${ }^{3}$ Marmara University, Faculty of Arts and Science, Department of Biology, Istanbul, Turkey
}

ORCID IDs of the authors: N.G.S. 0000-0003-1255-5188; K.D. 0000-0002-4582-3911; G.K. 0000-0002-4899-1494; F.V. 0000-0002-1051-5628

Please cite this article as: Goren Saglam N, Duygun K, Kaya G, Vardar F. Karrikinolide Promotes Seed Germination but Has no Effect on Leaf Segment Senescence in Triticum aestivum L.. Eur J Biol 2019; 78(2): 69-74. DOI: 10.26650/EurJBiol.2019.0005

\begin{abstract}
Objective: Germination and senescence are the two most important developmental processes in the plant life cycle. While seed germination is an important physiological event for the continuity of species, leaf senescence is also an important developmental process that impacts crop yields. Karrikins are a group of plant growth regulators found in the smoke generated by burning plant material. It has been suggested that karrikinolide (KAR1) is generally the most active karrikin in terms of stimulating germination.
\end{abstract}

Materials and Methods: In this study, the effect of karrikinolide on germination and leaf segment senescence in wheat was investigated. For this purpose, control, $1 \mathrm{nM}, 0.01,0.1,1$, and $10 \mu \mathrm{M} \mathrm{KAR}$ solutions were used. Firstly, the wheat seeds were germinated in the dark in these solutions and germination percentages and root lengths were measured. Secondly, 4 of first leaf segments $\left(3 \mathrm{~cm}\right.$. each) from 10-day-old wheat seedlings were placed in petri dishes containing 1, 10, $100 \mu \mathrm{M} K A R_{1}$ and distilled water as a control. Following incubation, fresh weight, chlorophyll content, cell death amounts and total protein amounts were determined.

Results: The obtained data shows that $1 \mu \mathrm{M}$ KAR 1 promotes germination and root length to the greatest extent. This suggests that karrikins have a promoting effect on the germination of wheat seeds. Our results demonstrate that KAR 1 has no effect on leaf segment senescence.

Conclusion: Our study suggests that KAR 1 has the potential to be used in agriculture to improve germination and seedling growth of crop species.

Keywords: Seed germination, leaf senescence, KARı, Triticum aestivum

\section{INTRODUCTION}

Germination and senescence are the two most important developmental events in plant life. While the life cycle of plants begins with seed germination in higher plants, senescence is the last phase of the plant life cycle. Seed germination is an important physiological event for the continuity of species. Internal and external conditions must be suitable for seed germination. Germination is controlled by external environmental factors and internal factors such as plant growth regulators $(1,2)$. Gibberellic acid $(G A)$ and abscisic acid (ABA) are well-known plant hormones that have an important role in the regulation of dormancy and germination (3-5). In addition, plant-derived smoke has been shown to promote the germination of numerous plant species with different life histories (68). These findings led to the discovery of compounds found in smoke (e.g. karrikins and glyceronitrile) that are responsible for the stimulation of germination $(6,9)$. Researchers have found that karrikinolide $\left(K A R_{1}\right)$ is the most abundant and active karrikin in smoke and that enhances germination and seedling growth in many plants even at very low concentrations $(7,8,10-12)$. 
Leaf senescence is an important developmental stage affected by various internal and external factors, such as leaf age, hormone levels, exposure to darkness, and environmental stresses $(13,14)$. Hormones are internal components that mediate the regulatory effects of environmental factors on leaf senescence. While some hormones such as ethylene, ABA, jasmonic acid (JA) and salicylic acid (SA) stimulate senescence, cytokinins and gibberellins play an important role in delaying senescence (15-19). In addition to these hormones, strigolactones (SLs) appear to be a class of plant hormones that regulate leaf senescence, because SL-deficient and SL-insensitive mutants show a phenotype with delayed leaf senescence (14). Karrikins and strigolactones have a butenolide ring in their structure. Even though both molecules have highly similar signaling mechanisms, it has been suggested that they have different effects on plant growth (20).

In literature, there has been no study showing the effect of karrikins on senescence so far. Our study is thus the first attempt to show the effect of KAR 1 on leaf segment senescence in wheat. For this reason, the aims of the current study were to investigate the effects of $K_{1} R_{1}$ on seed germination and leaf segment senescence in wheat.

\section{MATERIALS AND METHODS}

\section{Plant Material, Growth Conditions \& Hormone Treatments}

For the germination experiments, wheat (Triticum aestivum L.) seeds were sterilized with $10 \%$ commercial bleach and washed 5 times with sterile distilled water. Five replicates of 100 seeds each were placed in Petri dishes containing filter paper imbibed in a solution of $\mathrm{KAR}_{1}(1 \mathrm{~nm}, 0.01,0.1,1,10 \mu \mathrm{M})$ and distilled water as a control and kept in darkness at $25^{\circ} \mathrm{C}$. The wheat seeds were germinated in the dark in these solutions and germination percentages and root lengths were measured.

For the leaf segment senescence experiments, wheat seeds were planted in moisturized perlite after surface sterilization with $10 \%$ commercial bleach and washed 5 times with sterile distilled water. They were grown in a growth chamber $(16 \mathrm{~h}$ light, $8 \mathrm{~h}$ dark photoperiod and at $25 \pm 2{ }^{\circ} \mathrm{C}$ ). Four of the first leaf segments $(3 \mathrm{~cm}$. each) from 10-day-old wheat seedlings were placed in $5 \mathrm{~cm}$ diameter petri dishes containing $4 \mathrm{~mL}$ of $\mathrm{KAR}_{1}$ solutions $(1,10,100 \mu \mathrm{M})$. Distilled water was used as a control.

\section{Fresh Weight Analysis for Senescence}

After the harvest, the segments of wheat were weighed and placed in 1, 10 and $100 \mu \mathrm{M} \mathrm{KAR}$ solutions. After 10 days, the segments were weighed and the fresh weight change was calculated. It was analysed with 10 replicate tissue samples of 4 bulked leaf segments.

\section{Analysis of Pigment Content for Senescence}

The pigments were extracted by grinding the wheat segments in $90 \%$ ice-cold acetone with a pestle and mortar and added to a $15 \mathrm{~mL}$ tube. The samples were stored at $4{ }^{\circ} \mathrm{C}$ in the dark overnight. They were spun at $3000 \mathrm{~g}$ for $10 \mathrm{~min}$ at $4{ }^{\circ} \mathrm{C}$ in a centrifuge and the supernatant was collected in a new tube. The total chlorophyll content was determined spectrophotometrically (Shimadzu 1601) (21). It was analysed with 10 replicate tissue samples of 4 bulked leaf segments.

\section{Measurement of Cell Death for Senescence}

Cell death was measured spectrophotometrically using Evans blue to stain the detached leaves (22). The detached leaves were submerged in a $0.1 \%(\mathrm{w} / \mathrm{v})$ aqueous solution of Evans blue dye (Sigma-Aldrich). They were subjected to two 5 -min cycles of vacuum followed by 30 min under vacuum. The leaves were then washed three times with distilled water (15 min each). The dye bound to dead cells was solubilized in $50 \%(\mathrm{v} / \mathrm{v})$ methanol and $1 \%(\mathrm{w} / \mathrm{v})$ SDS at $60{ }^{\circ} \mathrm{C}$ for $30 \mathrm{~min}$ and then quantified by absorbance at $600 \mathrm{~nm}$. For $100 \%$ cell death, the detached leaves were heated at $100{ }^{\circ} \mathrm{C}$ for $5 \mathrm{~min}$ before staining. Four leaves were pooled for each sample. Ten samples were analysed and this experiment was repeated three times with equivalent results.

\section{Analysis of Protein Content for Senescence}

The segment samples were homogenized with an ice-cold 0.1 $\mathrm{mmol} / \mathrm{L}$ sodium phosphate buffer $(\mathrm{pH}$ 7.0). The homogenates were centrifuged at $13000 \mathrm{rpm}$ for $30 \mathrm{~min}$ at $4{ }^{\circ} \mathrm{C}$ and the supernatants were used to determine the total soluble protein content. The protein content of the extracts was determined according to Bradford (1976), using bovine serum albumin as a standard (23). It was analyzed with 10 replicate tissue samples of 4 bulked leaf segments.

\section{Statistical Analysis}

Each treatment was analysed with 10 replicate root and segment samples. The data presented here is the mean values \pm SE $(n=10)$. All data was evaluated using one-way ANOVA followed by Dunnett's multiple comparison tests using Graph Pad PRISM software. ${ }^{*} p<0.05$ was considered significant, $p>$ 0.05 was considered not significant.

\section{RESULTS}

\section{KAR1 Has a Stimulating Effect on the Germination and Root} Growth of Wheat Seeds

To investigate the effect of different concentrations of KAR 1 on wheat seed germination we calculated the germination percentage. Our results showed that $\mathrm{KAR}_{1}$ increased the germination percentage even at $1 \mathrm{nM}$ concentration ( $p$ $<0.05$ ). However, $1 \mu \mathrm{M} \mathrm{KAR} 1$ was found to be the most effective concentration with $100 \%$ germination percentage. It increased the germination by 1.3 times compared to the control (Figure 1). When the root length data was examined, it was seen that the root length compared to the control increased in all concentrations and the most effective concentration was found to be $1 \mu \mathrm{M} \mathrm{KAR} 1(p<0.05)$ (Figure 2 ). It was found 2.2 times higher compared to the control at $72^{\text {th }}$ hours. Our data indicated that $\mathrm{KAR}_{1}$ promotes seed germination and increases root length even at lower concentrations ( $1 \mathrm{~nm} \mathrm{KAR}$ ). 


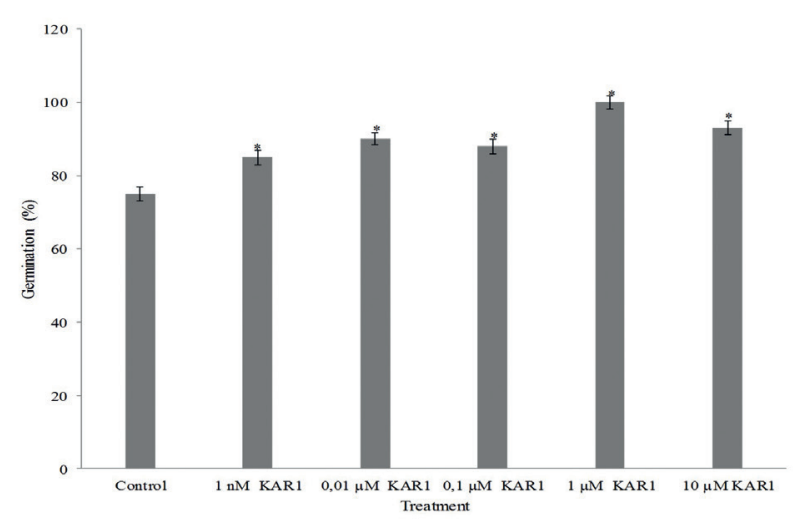

Figure 1. Comparisons of germination (\%) after incubation in distilled water (control), $1 \mathrm{nM}, 0.01,0.1,1$ and $10 \mu \mathrm{M} \mathrm{KAR} 1$ solutions. Values are means \pm S.E $(n=10) .{ }^{*} p<0.05$; compared to control)

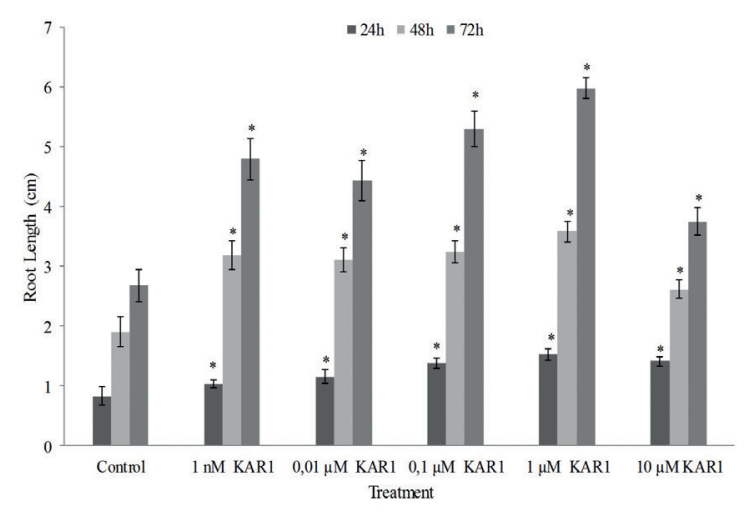

Figure 2. Comparisons of root lenght $(\mathrm{cm})$ after $24 \mathrm{~h}, 48 \mathrm{~h}$ and $72 \mathrm{~h}$ after incubation in distilled water (control), $1 \mathrm{nM}, 0.01,0.1$, 1 and $10 \mu \mathrm{M} \mathrm{KAR} 1$ solutions. Values are means \pm S.E $(n=10) .\left({ }^{*} \mathrm{p}<\right.$ 0.05 ; compared to control)

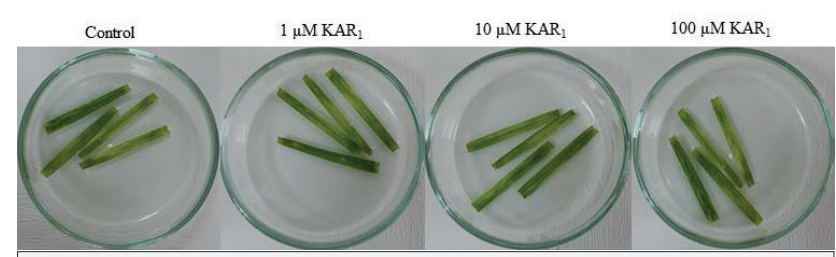

Figure 3. Wheat leaf segments after incubation in distilled water (control), 1, 10 and $100 \mu \mathrm{M} \mathrm{KAR}$, solutions, respectively.

\section{KAR $_{1}$ Does Not Show Any Promoting or Inhibitory Effect on Leaf Senescence}

There are no studies showing the relationship between KAR and leaf senescence. We designed this research to investigate the effect of $K A R_{1}$ on leaf segment senescence in wheat. The leaf segments were incubated in 1, 10 and $100 \mu \mathrm{M} \mathrm{KAR}_{1}$ solutions and distilled water (as a control). We found that there was no significant change between the control and treatment groups (Figure 3). The amounts of fresh weight observed in wheat segments soaked in 100, 10 and $1 \mu \mathrm{M} \mathrm{KAR}_{1}$ solutions are given in Figure 4. Fresh weight was calculated by subtracting the final weights of the segments recorded after being soaked in $\mathrm{KAR}_{1}$ solutions from their initial weights recorded before being soaked in $\mathrm{KAR}_{1}$ solutions. It was determined that exposure to the control or KAR 1 treatments did not make a lot of difference $(p>0.05)$ (Figure 4).

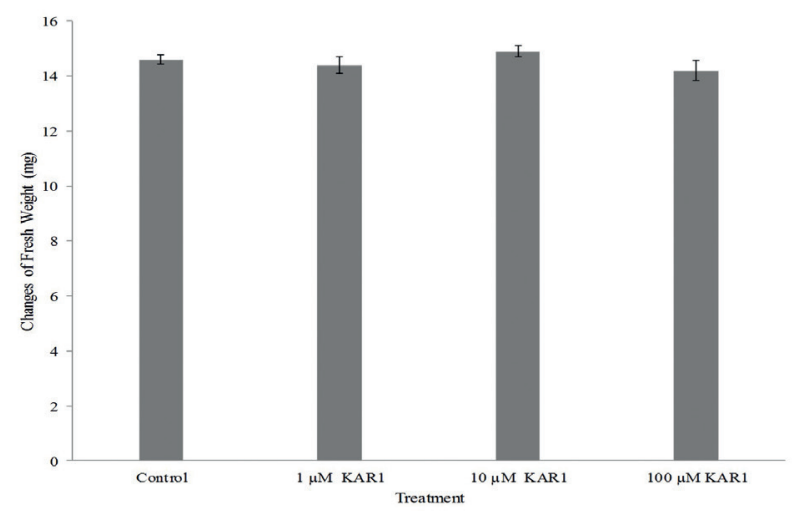

Figure 4. Comparisons of fresh weight after incubation in distilled water (control), 1, 10 and $100 \mu \mathrm{M} \mathrm{KAR}$ solutions. Values are means \pm S.E $(n=10) .(p>0.05$; compared to control)

A loss of chlorophyll is the first visible symptom of leaf senescence. We measured the chlorophyll content and did not find a significant change $(p>0.05)$ (Figure 5). Cell death was indicated by a loss of plasma membrane integrity. An examination of cell viability showed that cell death was not significantly altered in the treatment group, as measured by Evans blue staining. Evans blue measures cell death for an entire leaf. Our results showed that different concentrations of $K A R_{1}$ had no effect on cell death amounts when compared to the control ( $p>0.05$ ) (Figure 6). Another senescence parameter is total protein amount. The amounts of total protein observed

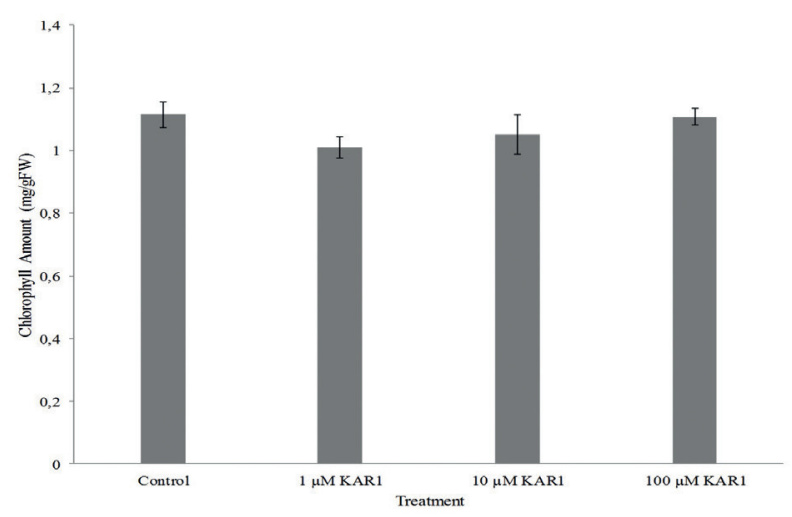

Figure 5. Effects of 1,10 and $100 \mu \mathrm{M} \mathrm{KAR}_{1}$ treatments on chlorophyll content in wheat leaf segments. Values are means \pm S.E $(n=10) .(p>0.05$; compared to control) 


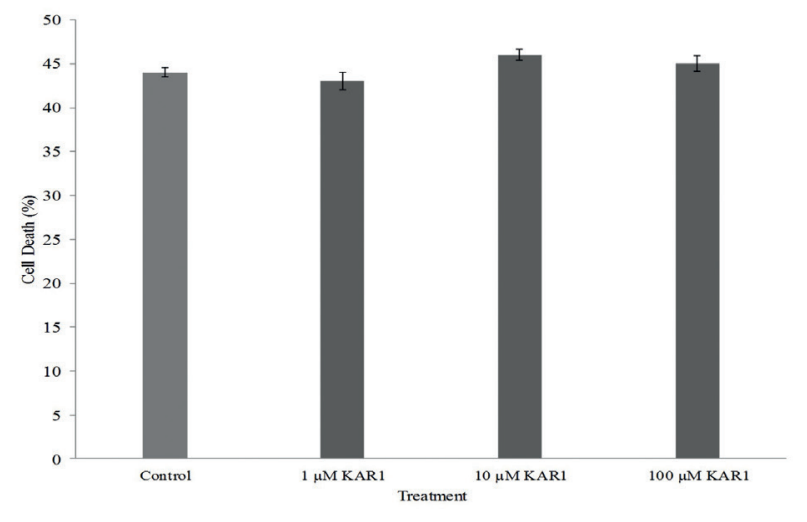

Figure 6. Effects of 1,10 and $100 \mu \mathrm{M}$ KAR1 treatments on cell death amount. Values are means \pm S.E $(n=10) .(p>0.05$; compared to control)

in wheat segments soaked in 100, 10 and $1 \mu \mathrm{M} \mathrm{KAR}{ }_{1}$ solutions are given in Figure 7. Our results showed that different concentrations of $\mathrm{KAR}_{1}$ had no effect on total protein amount when compared to the control $(p>0.05)$ (Figure 7).

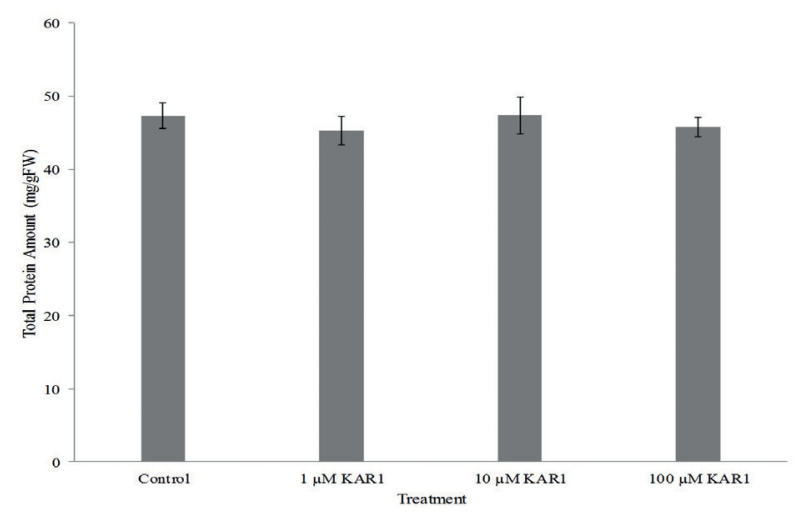

Figure 7. Effects of 1,10 and $100 \mu \mathrm{M}$ KAR1 treatments on total protein amount. Values are means \pm S.E $(n=10) .(p>0.05$; compared to control)

\section{DISCUSSION}

Seed germination and leaf senescence are important developmental processes that are affected by external and internal factors. Many plant hormones regulate seed germination and the initiation of leaf senescence. In recent years researchers have discovered new plant growth regulators such as karrikins. The discovery of karrikins is extremely important because of their potential usage in agriculture and horticulture. KAR1 was discovered in 2004 (6) and following this discovery, studies on the karrikins have always been on the effect of seed germination and seedling growth $(11,24-28)$. When the previous studies are examined, it is seen that there are no studies concerning the effect of $K A R_{1}$ on the germination of wheat seeds and on leaf senescence.
Global warming is causing a reduction in the productivity and survival of plants - including crops (29). It also adversely affects seed germination. Due to the role of wheat in nutrition, promoting the germination of wheat seeds is very important for yielding more crops from cultivated areas. For these reasons, it is important to identify new substances that will promote seed germination and to investigate their effectiveness. There is limited information on the effect of $K A R_{1}$ on germination in wheat seeds. To investigate the effect of $\mathrm{KAR}_{1}$ on the germination of wheat seeds, we used different concentrations of $\mathrm{KAR}_{1}$, ranging from $1 \mathrm{~nm}$ to $10 \mu \mathrm{M}$. Researchers found that $10 \mathrm{~nm} \mathrm{KAR} 1$ was an effective concentration for germination of lettuce seeds $(26,30)$. Our results showed that $1 \mu M K_{1} R_{1}$ was an effective concentration for wheat seeds. $1 \mu \mathrm{M} \mathrm{KAR} 1$ accelerated both seed germination and root length. Our results indicate that $K A R_{1}$ is effective in stimulating root growth as previously suggested (31).

Senescence is a developmental process that results in the death of a cell, organ or organism. Considering the remobilisation and recycling of important nutrients such as nitrogen, sulphur, phosphorus and potassium, we can clearly see the vital importance of senescence in the plant life cycle. These nutrients are remobilised from the senescing leaves to the actively growing tissues, thus providing for the growth and reproduction of the plant $(32,33)$. The photosynthetic capacity of the leaf suddenly drops due to the loss of chlorophyll during senescence. The production of carbohydrates, amino acids and other molecules is displaced by the degradation of macromolecules such as protein, lipids and nucleic acids (DNA and RNA), and the released nutrients are mobilised to plant parts such as new buds, young leaves, developing fruits and seeds or to storage organs for the future growing season $(34,35)$.

Initiation of leaf senescence is affected by various factors including age, abiotic and biotic stress, and plant hormones $(36,37)$. Effects of plant hormones on senescence such as auxin, cytokinin, gibberellin, ethylene ABA, SA and JA are well-known $(29,35,36)$. Moreover, the effect of KAR 1 on leaf senescence is still lacking in the literature. To test the effect of $K A R_{1}$ on wheat leaf segment senescence, different concentrations of KAR from 1 to $100 \mu \mathrm{M}$ were used. We measured important leaf senescence parameters such as, chlorophyll amount, fresh weight changes, cell death amount and total protein amount.

Changes in fresh weight are one indication of leaf senescence because nutrients remobilise from senescing leaves to storage organs during senescence $(38,39)$. The fresh weight tends to decrease when leaf senescence starts. Our data showed that there were no significant changes between the control and treatment groups (Figure 4). The dramatic metabolic transition from anabolism to catabolism, including the increased hydrolysis of macromolecules occurs during leaf senescence (38). Leaf cells are subject to structural and biochemical changes during senescence (40-44). Because of this, the changes of fresh weight are an important parameter for leaf senescence. 
Another important leaf senescence indicator is a decreased chlorophyll amount. During leaf senescence, the death of the photosynthesizing tissues occurs and this results in chlorophyll catabolism (42-44). A yellowing of the leaves is the most obvious phenotypic change in leaf senescence (45). It is caused by the dismantling of the pigment-protein complexes of chloroplasts and a degradation of the constituent chlorophyll (46). We measured the chlorophyll amounts and did not see any significant changes compared to the control (Figure 5).

Membrane integrity is crucial to cell viability. High levels of membrane integrity loss are clear symptoms of cell death (47, 48). The percentage of death cells is an important parameter for leaf senescence. In parallel with our results, we did not detect any changes in cell death amounts compared to the control groups (Figure 6). Our results related to leaf senescence show that $K A R_{1}$ does not have any effect on leaf segment senescence in the $1-100 \mu \mathrm{M}$ concentration range.

Biochemically, senescence is characterized by the degradation of macro-molecules, such as chlorophylls, proteins, membrane lipids and RNA, and metabolically these events replace carbon assimilation (49). In our study we found no changes in protein content following the KAR1 application (Figure 7).

\section{CONCLUSION}

In the light of this data, this study suggests that KAR 1 promotes seed germination even at $1 \mathrm{nM}$ in wheat. Our results indicate that $1 \mu M K_{A R}$ is more effective for promoting seed germination in wheat seeds. However, neither a stimulatory nor inhibitory effect of $K A R_{1}$ on the leaf segment senescence in wheat leaves was observed.

Peer-review: Externally peer-reviewed.

Author Contributions: Conception/Design of study: N.G.S., F.V.; Data Acquisition: N.G.S.; Data Analysis/Interpretation:N.G.S., K.D., G.K.; Final Approval and Accountability: N.G.S., K.G., G.K., F.V.; Drafting Manuscript: N.G.S.; Critical Revision of Manuscript: N.G.S.; Technical or Material Support: N.G.S., K.G., G.K., F.V.

Conflict of Interest: The authors declare that they have no conflicts of interest.

Financial Disclosure: There are no funders to report for this submission

Acknowledgements: The authors would like to thank to Dr. Gavin R. Flametti (University of Western Australia) for gifting the Karrikinolide.

\section{REFERENCES}

1. Yuan K, Wysocka-Diller J. Phytohormone signalling pathways interact with sugars during seed germination and seedling development. J Exp Bot 2006; 57(12):3359-67.

2. Merai, Z, Graeber K, Wilhelmsson P, Ullrich KK, Arshad W, Grosche $C$ et al., A novel model plant to study the light control of seed germination. J Exp Bot 2019; erz146, doi:10.1093/jxb/erz146
3. Koornneef $M$, Bentsink $L$, Hilhorst $H$. Seed dormancy and germination. Curr Opin Plant Biol 2002; 5(1):33-6.

4. Penfield S. Seed dormancy and germination. Curr Biol 2017; 27(17):R874-78.

5. Kępczyński J. Induction of agricultural weed seed germination by smoke and smoke-derived karrikin (KAR 1), with a particular reference to Avena fatua L. Acta Physiol Plant 2018; 40(5):87-97.

6. Flematti GR, Ghisalberti EL, Dixon KW, Trengove RD. A compound from smoke that promotes seed germination. Science 2004; 305(5686):977-77.

7. Light ME, Daws MI, Van Staden J. Smoke-derived butenolide: towards understanding its biological effects. S Afr J Bot 2009; 75(1):1-7.

8. Flematti GR, Dixon KW, Smith SM. What are karrikins and how were they 'discovered'by plants? BMC Biol 2015; 13(1):108-12.

9. Flematti GR, Merritt DJ, Piggott MJ, Trengove RD, Smith SM, Dixon KW, Ghisalberti EL. Burning vegetation produces cyanohydrins that liberate cyanide and stimulate seed germination. Nat Commun 2011; 2:360. doi: 10.1038/ncomms1356

10. Nelson DC, Flematti GR, Ghisalberti EL, Dixon KW, Smith SM. Regulation of seed germination and seedling growth by chemical signals from burning vegetation. Annu Rev Plant Biol 2012; 63:107-30.

11. Reynolds CJ, Long RL, Flematti GR, Cherry H, Turner SR. Karrikins promote germination of physiologically dormant seeds of $C$ hrysanthemoides monilifera ssp. monilifera (boneseed). Weed Res 2014; 54(1):48-57.

12. Waters MT. From little things big things grow: karrikins and new directions in plant development. Func Plant Biol 2017; 44(4):373-85.

13. Sharabi-Schwager M, Samach A, Porat R. Overexpression of the CBF2 transcriptional activator in Arabidopsis counteracts hormone activation of leaf senescence. Plant Signaling Behav 2010; 5(3):296-99.

14. Yamada Y, Furusawa S, Nagasaka S, Shimomura K, Yamaguchi S, Umehara M. Strigolactone signaling regulates rice leaf senescence in response to a phosphate deficiency. Planta 2014; 240(2):399408

15. Morris K, Mackerness SAH, Page T, John CF, Murphy AM, Carr JP, Buchanan-Wollaston $\mathrm{V}$. Salicylic acid has a role in regulating gene expression during leaf senescence. The Plant J 2000; 23(5):677-85.

16. He Y, Fukushige $H$, Hildebrand DF, Gan S. Evidence supporting a role of jasmonic acid in Arabidopsis leaf senescence. Plant Physiol 2002; 128(3):876-84.

17. Lim PO, Nam HG. Aging and senescence of the leaf organ. J Plant Biol 2007; 50(3):291-300.

18. Jibran R, Hunter DA, Dijkwel PP. Hormonal regulation of leaf senescence through integration of developmental and stress signals. Plant Mol Biol 2013; 82(6):547-61.

19. Yamada $Y$, Umehara M. Possible roles of strigolactones during leaf senescence. Plants 2015; 4(3):664-77.

20. Morffy N, Faure L, Nelson DC. Smoke and hormone mirrors: action and evolution of karrikin and strigolactone signaling. Trends Genet 2016; 32(3):176-88.

21. Parsons TR, Strickland JDH. Discussion of spectrophotometric determination of marine plant pigments, with revised equation for ascertaining chlorophylls and carotenoids. J Mar Res 1963; 21:155-63.

22. Guo FQ, Crawford NM. Arabidopsis nitric oxide synthase1 is targeted to mitochondria and protects against oxidative damage and dark-induced senescence. The Plant Cell 2005; 17(12):3436-50.

23. Bradford MM. A rapid and sensitive method for the quantitation of microgram quantities of protein utilizing the principle of proteindye binding. Anal Biochem 1976; 72: 248-54. 
24. Nelson DC, Flematti GR, Riseborough JA, Ghisalberti EL, Dixon KW, Smith SM. Karrikins enhance light responses during germination and seedling development in Arabidopsis thaliana. Proc Natl Acad Sci USA 2010; 107:7095-100.

25. Light ME, Burger BV, Staerk D, Kohout L, Van Staden J. Butenolides from plant-derived smoke: natural plant-growth regulators with antagonistic actions on seed germination. J Nat Prod 2010; 73(2):267-69.

26. Nair JJ, Pošta M, Papenfus HB, Munro OQ, Beier P, Van Staden J. Synthesis, $\mathrm{X}$-ray structure determination and germination studies on some smoke-derived karrikins. S Afr J Bot 2014; 91:53-7.

27. Mousavinik M, Jowkar A, Rahimianboogar A. Positive effects of karrikin on seed germination of three medicinal herbs under drought stress. Iran Agric Res 2016; 35(2):57-64.

28. Laghmouchi Y, Belmehdi O, Bouyahya A, Senhaji NS, Abrini, J. Effect of temperature, salt stress and $\mathrm{pH}$ on seed germination of medicinal plant Origanum compactum. Biocatal Agric Biotechnol 2017; 10:156-60.

29. Zhao Y, Gao J, Kim J, Chen K, Bressan RA, Zhu JK. Control of plant water use by $A B A$ induction of senescence and dormancy: an overlooked lesson from evolution. Plant Cell Physiol 2017; 58(8):1319-27.

30. Flematti GR, Goddard-Borger ED, Merritt DJ, Ghisalberti EL, Dixon KW, Trengove RD. Preparation of $2 \mathrm{H}$-furo [2, 3-c] pyran-2one derivatives and evaluation of their germination-promoting activity. J Agric Food Chem 2007; 55(6):2189-94.

31. Çatav ŞS, Küçükakyüz K, Tavşanoğlu Ç, Pausas JG. Effect of firederived chemicals on germination and seedling growth in Mediterranean plant species. Basic Appl Ecol 2018; 30:65-75.

32. Balazadeh S, Parlitz S, Mueller-Roeber B, Meyer RC. Natural developmental variations in leaf and plant senescence in Arabidopsis thaliana. Plant Biol 2008; 10:136-47.

33. Kitonyo OM, Sadras VO, Zhou Y, Denton MD. Nitrogen supply and sink demand modulate the patterns of leaf senescence in maize. Field Crop Res 2018; 225:92-103.

34. Maillard A, Diquelou S, Billard V, Laine P, Garnica M, Prudent M, et al. Leaf mineral nutrient remobilization during leaf senescence and modulation by nutrient deficiency. Front Plant Sci 2015; 6: 317-22.

35. Tamary E, Nevo R, Naveh L, Levin-Zaidman S, Kiss V, Savidor A, et al. Chlorophyll catabolism precedes changes in chloroplast structure and proteome during leaf senescence. Plant Direct 2019; 3(3): e00127.
36. Kim J, Woo HR, Nam HG. Toward systems understanding of leaf senescence: an integrated multi-omics perspective on leaf senescence research. Mol Plant 2016; 9(6):813-25.

37. Ding F, Wang M, Zhang, S. Sedoheptulose-1, 7-bisphosphatase is involved in methyl jasmonate-and dark-induced leaf senescence in tomato plants. Int J Mol Sci 2018; 19(11):3673-80.

38. Woo HR, Kim HJ, Lim PO, Nam HG. Leaf senescence: Systems and dynamics aspects. Annu Rev Plant Biol 2019; 70:15.1-15.30.

39. Jan S, Abbas N, Ashraf M, Ahmad P. Roles of potential plant hormones and transcription factors in controlling leaf senescence and drought tolerance. Protoplasma 2019; 256(2):313-29.

40. Gregersen PL, Culetic A, Boschian L, Krupinska K. Plant senescence and crop productivity. Plant Mol Biol 2013; 82:603-22.

41. Li X, Ahmad S, Ali A, Guo C, Li H, Yu J, Guo Y. Characterization of somatic embryogenesis receptor-like kinase 4 as a negative regulator of leaf senescence in arabidopsis. Cells 2019; 8(1):50-61.

42. Lim J, Park JH, Jung S, Hwang D, Nam HG, Hong S. Antagonistic roles of PhyA and PhyB in far-red light-dependent leaf senescence in Arabidopsis thaliana. Plant Cell Physiol 2018; 59(9):1753-64.

43. Krautler B. Breakdown of chlorophyll in higher plants- phyllobilins as abundant, yet hardly visible signs of ripening, senescence, and cell death. Angewandte Chemie 2016; 55:4882-907.

44. Lim PO, Kim HJ, Nam HG. Leaf Senescence. Annu Rev Plant Biol 2007; 58:115-36.

45. Kim HJ, Park JH, Kim J, Kim JJ, Hong S, Kim J et al. Time-evolving genetic networks reveal a NAC troika that negatively regulates leaf senescence in Arabidopsis. PNAS 2018; 115(21):E4930-39.

46. Mayta ML, Lodeyro AF, Guiamet JJ, Tognetti VB, Melzer M, Hajirezaei MR, Carrillo N. Expression of a plastid-targeted flavodoxin decreases chloroplast reactive oxygen species accumulation and delays senescence in aging tobacco leaves. Front Plant Sci 2018; 9:1039-57.

47. Blasi ÉA, Buffon G, Rativa AG, Lopes MC, Berger M, Santi L. et al. High infestation levels of Schizotetranychus oryzae severely affects rice metabolism. J Plant Physiol 2017; 219:100-111.

48. Cheng R, Gong L, Li Z, Liang, YK. Rice BIG gene is required for seedling viability. J Plant Physiol 2019; 232:39-50.

49. Balazadeh S, Riaño-Pachón DM, Mueller-Roeber B. Transcription factors regulating leaf senescence in Arabidopsis thaliana. Plant Biol 2008; 10: 63-75. 